\title{
Power Flow Regulation of a Multi Area System with Fuzzy Gain Scheduled PI (FGPI) Controller for Static Synchronous Series Compensator (SSSC) with Superconducting Magnetic Energy Storage System (SMES)
}

\author{
S. Padma \\ Asst. Prof., EEE \\ Sona College of Technology, \\ Salem, TN, India, 636005
}

\author{
Dr. R. Lakshmipathi \\ Prof., EEE \\ St. Peter's Engineering College, \\ Chennai, TN, India
}

\begin{abstract}
In this study, a fuzzy gain scheduled proportional and integral (FGPI) controller was developed to regulate the power flow regulation of Static Synchronous Series Compensator (SSSC) in a multi-area power system. Also, this FGPI was developed for the SSSC without and with Superconducting Magnetic Energy Storage (SMES) system. Two performance criteria were utulized for the comparison. First, settling times and overshoots of the real and reactive power flow were compared. Later, the THD of the Voltage Source Inverter (VSI) output voltage were compared. All the models were simulated by Matlab 7.0-Simulink software. The simulation results show that the FGPI controller developed in this study performs better for the SSSC system with SMES than the other without SMES.
\end{abstract}

\section{General Terms}

Fuzzy Logic Control, multi-level inverters, PI control, FACTS devices

\section{Keywords}

Multi-area system, SSSC, Fuzzy Gain Scheduled PI controller.

\section{INTRODUCTION}

The demand for and dependence on electricity has become increased nowadays and due to this, the complexity of the power system network is increasing. The expansion of power system network and the transient stability are the main factors of concern nowadays. In order to solve the problems economically [1], the concept of Flexible AC Transmissions Systems (FACTS) technology was developed. The FACTS technology increases the operational efficiency and speed of response. The Static Synchronous Series Compensator (SSSC) is an important FACTS device which can allow rapid and continuous changes in the transmission line impedance so that the active power flow along the compensated transmission line can be maintained within a specified range under a wide range of operating conditions. Previous research has shown that while power system stabilizers (PSS) have been able to provide damping of system oscillations in some cases, they have not been universally successful, and FACTS devices are being increasingly used for this purpose [2].
Nowadays, the new Energy Storage System (ESS) is a feasible alternative to decrease the reserve power of generators. By using proper energy storage devices, excess energy may be stored to substitute the power reserve of generators during the action of the primary frequency control. In this sense, research in this field has been lately extended with the aim of incorporating power electronic devices into electric power systems. The goal pursued is to control the operation of the power system, a fact which clearly affects the operation security. In bulk power transmission systems, power electronics-based controllers are frequently called Flexible AC Transmission Systems (FACTS). Presently, these devices are a viable alternative as they allow controlling voltages and currents of appropriate magnitude for electric power systems at an increasingly lower cost

This paper presents an analysis of an FGPI controller for SSSC without and with SMES. The firing angle for the 48-pulse inverter of SSSC is given by the controller. Comparative studies of the proposed control schemes were carried out in the Matlab/Simulink Simpower Systems environment. With the case studies it is clear that the SSSC with the proposed FGPI controller can be effective in maintaining the power flow regulation of a power system by providing extra damping to power flow oscillations

\section{PRINCIPLE OF OPERATION OF SSSC}

SSSC is a voltage sourced converter based series compensator. The compensation works by increasing the voltage across the impedance of the given physical line, which in turn increases the corresponding line current and the transmitted power. For normal capacitive compensation, the output voltage lags the line current by $90^{\circ}$. With voltage source inverters the output voltage can be reversed by simple control action to make it lead or lag the line current by $90^{\circ}$. The single line diagram of the multimachine system used for the simulation study is shown in Fig. 1. The specifications of the test system are shown in Table 1 . 


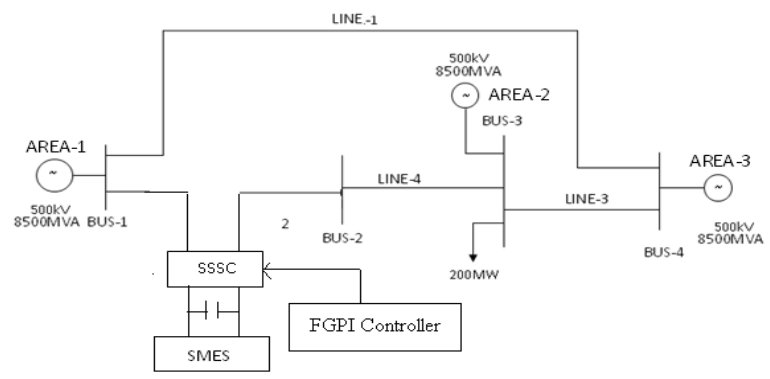

Figure 1 Single line diagram of the test system with SSSC.

Table 1. Specifications of the test system

\begin{tabular}{|c|c|}
\hline Parameters & Values \\
\hline Rated Voltage & $500 \mathrm{kV}$ \\
\hline Base Voltage & $500 \mathrm{kV}$ \\
\hline Resistance & $0.1 \mathrm{p.u}$ \\
\hline Reactance & $0.3 \mathrm{p} . \mathrm{u}$ \\
\hline Transmission line Resistane $\mathrm{R}_{\mathrm{L}}$ & $0.05 \mathrm{p} . \mathrm{u}$ \\
\hline Transmission line Reactance $\mathrm{X}_{\mathrm{L}}$ & $0.25 \mathrm{p} . \mathrm{u}$ \\
\hline DC Voltage & $20 \mathrm{kV}$ \\
\hline Capacitance & $2000 \mu \mathrm{F}$ \\
\hline Series Transformer - Rated Voltage & $20 \mathrm{kV} / 500 \mathrm{kV}$ \\
\hline Inductance for SMES & $12.5 \mathrm{H}$ \\
\hline
\end{tabular}

If $\mathrm{V}_{\mathrm{s}}$ and $\mathrm{V}_{\mathrm{r}}$ are the sending end and receiving end voltages, then the real and reactive power (P \& Q) flow at the receiving end can be expressed as

$$
P=\frac{V_{s} V_{r}}{X_{L}} \sin \left(\delta_{s}-\delta_{r}\right)=\frac{V^{2}}{X_{L}} \sin \delta
$$

and

$Q=\frac{V_{s} V_{r}}{X_{L}}\left(1-\cos \left(\delta_{s}-\delta_{r}\right)\right)=\frac{V^{2}}{X_{L}}(1-\cos \delta)$

The SSSC introduces a virtual compensating reactance, $\mathrm{X}_{\mathrm{q}}$ (both inductive and capacitive), in series with the transmission line inductive reactance $\mathrm{X}_{\mathrm{L}}$. Now the expressions for the real and reactive powers are, $P=\frac{V^{2}}{X_{e f f}} \sin \delta=\frac{V^{2}}{X_{L}\left(1-\frac{X_{q}}{X_{L}}\right)} \sin \delta$

and

$Q=\frac{V^{2}}{X_{e f f}}(1-\cos \delta)=\frac{V^{2}}{X_{L}\left(1-\frac{X_{q}}{X_{L}}\right)}(1-\cos \delta)$ where, $\mathrm{X}_{\mathrm{eff}}$ is the effective reactance of the transmission line, including the emulated variable reactance inserted through the injected voltage source supplied by the SSSC. $\mathrm{X}_{\mathrm{q}}$ is negative when the SSSC is operated in the inductive mode and positive when the SSSC is operated in the capacitive mode.

With 48 - pulse VSI, AC filters are not required. The inverter described is harmonic neutralized. The instantaneous values of the phase-to-phase voltage and the phase to neutral voltage of the 48 pulse inverter output voltage are expressed as Eq. (5) and (6)

$$
V_{a b_{48}}(t)=8 \sum V_{a b_{48}} \sin \left(m \omega t+18.75^{\circ} m+11.25^{\circ} t\right)
$$

$$
V_{a n_{48}}(t)=\frac{8}{\sqrt{3}} \sum_{m=1}^{\infty} V_{a n_{48}} \sin \left(m \omega t+18.75^{\circ} m-11.25^{\circ} t\right)
$$

Where,

$$
\begin{aligned}
& V_{a b_{48}}=\frac{4}{m \pi} V_{D C} \cos \frac{\pi}{6} m \\
& V_{a n_{48}}=\frac{4}{3 m \pi} V_{D C}\left(1+\cos \frac{\pi}{3} m\right)
\end{aligned}
$$

and

$\mathrm{m}=48 \mathrm{r} \pm \mathrm{i}, \mathrm{r}=0,1,2,$.

$\mathrm{i}=1$, for positive sequence harmonics and $\mathrm{i}=-1$, for negative sequence harmonics

The voltages $\mathrm{V}_{\mathrm{bc48}}$ and $\mathrm{V}_{\mathrm{ca} 48}$ exhibit a similar negative pattern except phase shifted by $120^{\circ}$ and $240^{\circ}$ respectively. Similarly, the phase voltages $\mathrm{V}_{\mathrm{bn} 48}$ and $\mathrm{V}_{\mathrm{cn} 48}$ are also phase shifted by $120^{\circ}$ and $240^{\circ}$ respectively.

\section{INTERNAL CONTROL SCHEME FOR SSSC}

The control scheme proposed earlier [3] is based on the line impedance control mode in which the SSSC compensating voltage is derived by multiplying the current amplitude with the desired compensating reactance $\mathrm{X}_{\mathrm{qref}}$. Since it is difficult to predict $X_{\text {qref }}$ under varying network contingencies, in the proposed scheme, the controller is modified as shown in fig. 2 to operate the SSSC in the automatic power flow control mode [4]. In this mode, the reference inputs to the controller are $\mathrm{P}_{\text {ref }}$ and $\mathrm{Q}_{\mathrm{ref}}$, which are to be maintained in the transmission line despite system changes. The instantaneous power is obtained in terms of d-q quantities as,

$P=\frac{3 V_{d} I_{d}}{2}$ and $Q=\frac{3 V_{q} I_{q}}{2}$

From the above equation, the power references are converted to current references as in equation (10). 


$$
I_{\text {dref }}=\frac{2 P_{r e f}}{3 V_{d}} \text { and } I_{q r e f}=\frac{2 Q_{r e f}}{3 V_{d}}
$$

The line current $I_{a b c}$ and the line voltage $V_{a b c}$ are sensed at the point B2 on the transmission line of Fig. 1 and are converted into $\mathrm{d}-\mathrm{q}$ components. The desired current references $\mathrm{I}_{\text {dref }}$ and $\mathrm{I}_{\mathrm{qref}}$ are compared with actual current components $I_{d}$ and $I_{q}$ respectively and the error signals are processed in the controller. Based on the controller parameters, the required small displacement angle $\beta$ to control the angle of the injected voltage with respect to the line current has been derived. A Phase Locked Loop (PLL) is used to determine the instantaneous angle $\theta$ of the three-phase line voltage $V_{a b c}$. The current components $I_{d}$ and $I_{q}$ of the three phase line currents are used to determine the angle $\theta_{i r}$ relative to the voltage $\mathrm{V}_{\mathrm{abc}}$. Depending upon the instantaneous reactive power with respect to the desired value either $(\pi / 2)$ is added (inductive) or subtracted (capacitive) with $\beta$. Thus, the required phase angle is derived as $\theta_{r e f}=\theta+\theta_{i r}+\beta \pm(\pi / 2)$. The modulation index $\mathrm{m}$ derived from the active power control part of the circuit and the phase angle $\theta_{\text {ref }}$ are applied to the PWM modulator to generate the SSSC compensating voltage. Using $\theta_{\text {ref }}$ and $\mathrm{m}$, the fundamental component of PWM inverter output voltage is obtained as in equation (11),

$V_{\text {sin } e}=m \sin \left(2 \pi f t-\theta_{\text {ref }}\right)$

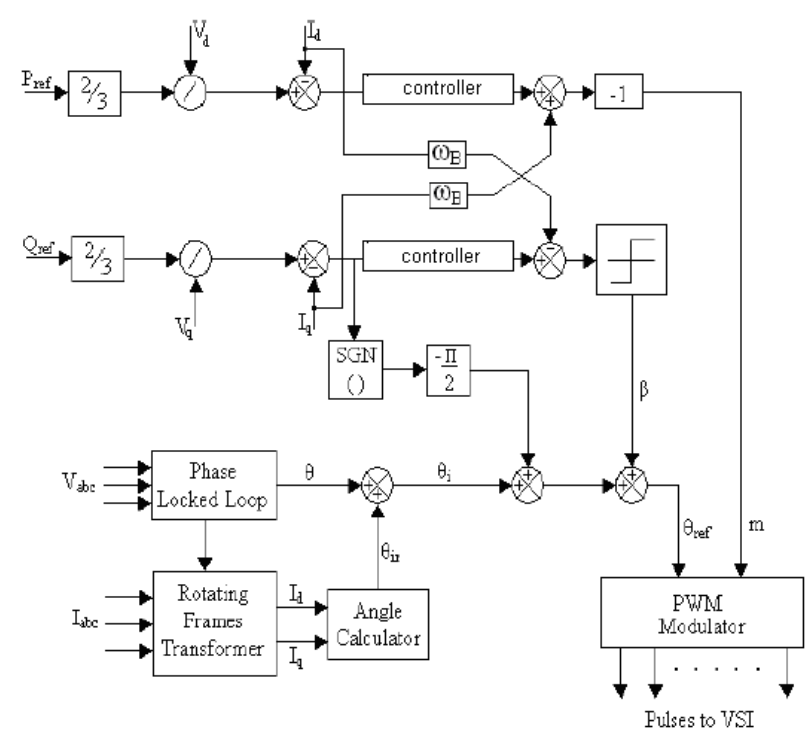

Figure 2. SSSC internal control scheme.

\section{Super Conducting Energy Storage System}

An electronic interface known as chopper is needed between the energy source and the VSI. For VSI the energy source compensates the capacitor charge through the electronic interface and maintains the required capacitor voltage. Two-quadrant n- phase DC-DC converter as shown in Fig. 3 is adopted as interface. Here ' $n$ ' is related to the maximum current driven by the superconducting device. The DC-DC chopper solves the problems of the high power rating requirements imposed by the superconducting coil to the SSSC. The DC-DC chopper allows to reduce the ratings of the overall power devices by regulating the current flowing from the superconducting coil to the inverter of the SSSC [9].

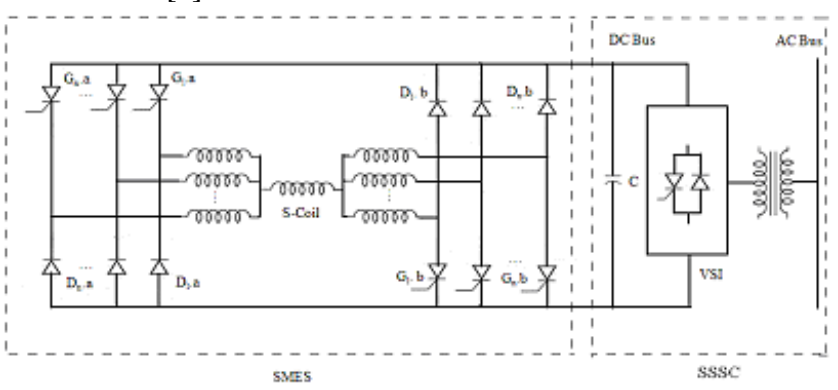

Figure 3. Circuit diagram of a chopper

The two quadrant multi-phase chopper is composed of many shunt connected diode-thyristor legs that permit the driving of the high current ratings stored in the superconducting coil. The chopper has three modes of operation to perform the charge, the discharge and the storage in the SMES device. The chopper is operated in a step down configuration in the charge mode of the superconducting coil. Here, the set of thyristors "a" are operated with the duty cycle ' $D$ ' while the set of thyristors " $b$ " are kept on at all times. The relationship between the coil voltage and the DC bus voltage is given by the equation,

$$
V_{\text {SMES }}=D \cdot V_{\text {dC }}
$$

Once the charging of the superconducting coil is completed, the operating mode of the DC-DC converter is changed to the standby mode for which the set of thyristors "a" are kept off all the time while the set of thyristors " $b$ " are kept on constantly. In the discharge mode, the chopper is operated in a step-up configuration. The set of thyristors " $b$ " is operated with duty cycle D while the set of thyristors "a" is kept off at all times. The relationship between the coil voltage and the DC bus voltage is given by the equation

$$
-V_{\text {SMES }}=(1-D) \cdot V_{d c}
$$

The duty cycle ranges from 0 to 1 . The relationship between the DC bus voltage and the output voltage of the inverter is given by the Eq. (14)

$$
V_{\text {dc }}=k_{a .}\left\|V_{i n v}\right\|
$$

Where $\mathrm{k}_{\mathrm{a}}=\mathrm{ka}$ is a constant associated with both the pulse number of the VSI (constant k) and the voltage ratio "a" of the coupling transformer.

For generating the gating pulses for VSI and the DCDC chopper, internal control block is designed. Fig. 5 shows the internal control scheme for proposed system [8]. The control scheme includes the decoupled control for the real and reactive power. 


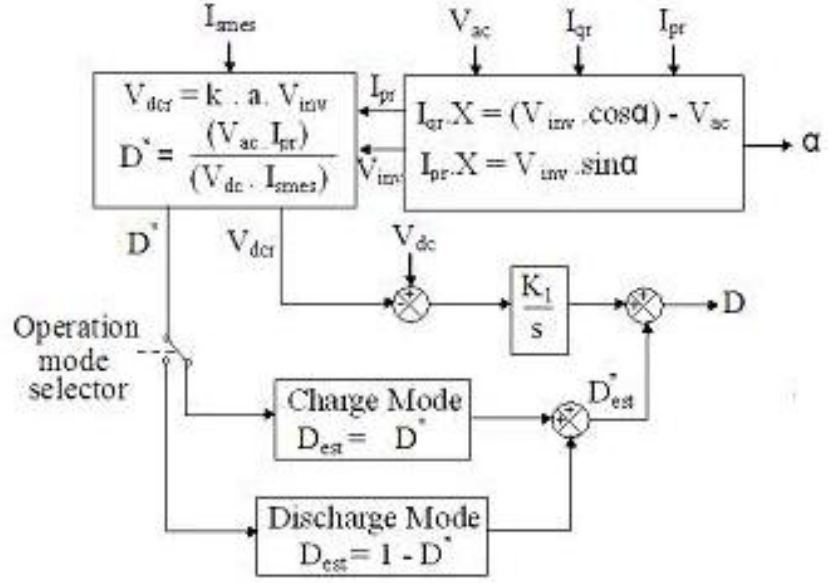

Figure 4. Internal control scheme for SSSC with SMES

The two independent reference signals are the reactive current and the active current. From these reference signals the amplitude and phase ratings of the voltage at the VSI is determined. The duty cycle $\mathrm{D}$ is estimated from the active power ratings that the SSSC should inject from the voltage at the DC bus and from the current stored into the SMES coil. This estimated value of Dest is adjusted through a closed loop control whose function is eliminating the voltage error between the calculated and the real voltage ratings at the DC bus.

\section{FUZZY GAIN SCHEDULED PI CONTROLLER}

Fuzzy set theory and fuzzy logic establish the rules of a nonlinear mapping [9]. The use of fuzzy sets provides a basis for a systematic way for the application of uncertain and indefinite models [10]. Fuzzy control is based on a logical system called fuzzy logic. It is much closer in spirit to human thinking and natural language than classical logical systems [11]. Nowadays, fuzzy logic is used in almost all sectors of industry and science. Because of complexity and multi-variable conditions of the power system, conventional control methods may not give satisfactory solutions. On the other hand, robustness and reliability make fuzzy controllers useful in solving wide range of control problems. Because of complexity and multi-variable conditions of the power system, conventional control methods may not give satisfactory solutions. On the other hand, robustness and reliability make fuzzy controllers useful in solving wide range of control problems [13].

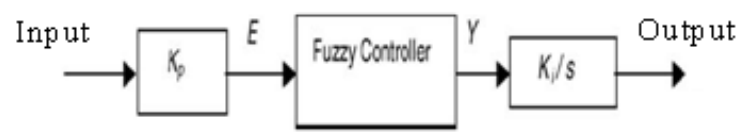

Figure 5. Simple FGPI controller strucure

Figure 5 shows the simple FGPI controller structure [14]. In the figure, $\mathrm{Kp}$ and $\mathrm{Ki}$ are the proportional and the integral gains, respectively. The fuzzy controller input can be derivative of error together with signal E. The fuzzy controller block is formed by

fuzzification, inference mechanism and defuzzification. Therefore, $\mathrm{Y}$ is a crisp value and $u$ is a control signal for the system. The error in Id and Iq are given as input signal to the controller of figure 2.

Most of experiments and simulation studies applied to the power systems are shown that the conventional controllers have large overshoots and long settling times [4]. Also, optimizing time for control parameters, especially PI controllers, is very long and the parameters are not calculating exactly. In addition, it has been known that conventional controllers generally do not work well for non-linear, higher order and time-delayed linear, and particularly complex and vague systems that have no precise mathematical models. According to many researchers, there are some reasons for the present popularity of fuzzy logic control.

(a)



(b)

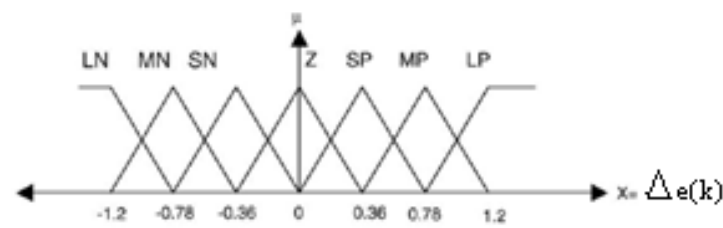

(c)

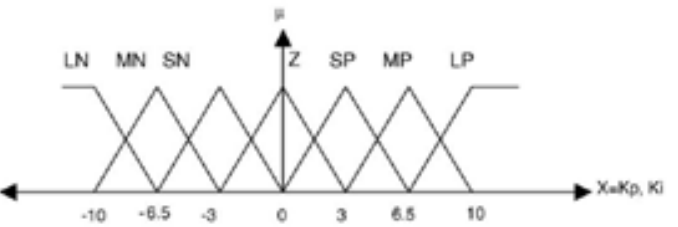

Figure 6 Membership function for fuzzy logic control

Table 2 FGPI controller rules

\begin{tabular}{|l|l|l|l|l|l|l|l|}
\hline \multicolumn{1}{|c|}{$\begin{array}{l}\mathrm{e} / \\
\mathrm{e}\end{array}$} & $\mathrm{LN}$ & $\mathrm{MN}$ & $\mathrm{SN}$ & $\mathrm{Z}$ & $\mathrm{SP}$ & $\mathrm{MP}$ & $\mathrm{LP}$ \\
\hline LN & LP & LP & LP & MP & MP & SP & Z \\
\hline MN & LP & MP & MP & MP & SP & ZE & SN \\
\hline SN & LP & MP & SP & Z & Z & SN & MN \\
\hline Z & MP & MP & Z & SN & SN & MN & MN \\
\hline SP & MP & SP & Z & SN & SN & MN & LN \\
\hline MP & SP & Z & SN & MN & MN & MN & LN \\
\hline LP & Z & SN & MN & MN & LN & LN & LN \\
\hline
\end{tabular}

LN: large negative; MN: medium negative; $\mathrm{SN}$ : small negative; Z: zero; SP: small positive; MP: medium positive; LP: large positive,

First, fuzzy logic can easily be applied to most industrial applications in industry. Second, it can deal with intrinsic 
uncertainties by changing controller parameters. Finally, it is appropriate for rapid applications. Therefore, fuzzy logic has been applied to the industrial systems as a controller. Human experts prepare linguistic descriptions as fuzzy rules, which are obtained based on step response experiments of the process, error signal, and its time derivative [9]. Determining the controller parameters with these rules, a PI controller generates the control signal by which, the fuzzy gain scheduling proportional and integral controller (FGPI) is formed. Fuzzy logic shows experience and preference through membership functions, which have different shapes depending on the experience of system experts. Inference mechanism is realized by seven rules for the FGPI controllers. The appropriate rules used in the study are given in Table 2. Membership functions shapes of the error and derivative error and the gains are chosen to be identical with triangular function for both fuzzy logic controllers. However, their horizontal axis ranges are taken different valuess. The membership function sets of FGPI controller for error and derivative of error, $K \mathrm{p}$ and $K \mathrm{i}$ are shown in Fig. 6 . Defuzzification has also been performed by the center of gravity method.

\section{SIMULATION RESULTS AND DISCUSSTIONS}

The FGPI control for SSSC without and with SMES are applied for the test system. Case (a) is discussed for the FGPI control for 48-pulse inverter based SSSC and case (b) is discussed for the FGPI control for 48-pulse inverter based SSSC with SMES and are simulated using MATLAB/Simulink to analyze its operation. A step change in real and reactive power are created to study the performance of the controllers.

Fig. 7 and 8 show wave forms of the series injected voltages for case (a) and (b) respectively. Fig. 9 and 10 show the reference and measured value of real and reactive power for case (a) and fig. 11 and 12 for case (b). It can be seen that the $\mathrm{P}_{\text {ref }}$ is initially at 0.87 p.u and changes to 0.93 p.u at time $0.25 \mathrm{~s}$ and $\mathrm{Q}_{\text {ref }}$ changes from -0.6 to 0.1 p.u at time $0.5 \mathrm{~s}$. It is clear from the figures that the performance of FGPI controller for case (b) is better compared to case (a).

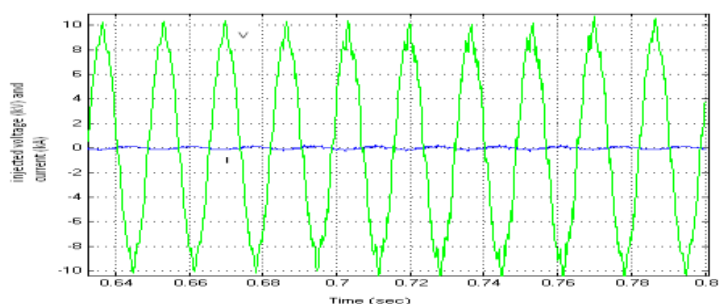

Figure 7. SSSC injected voltage and current for case (a)

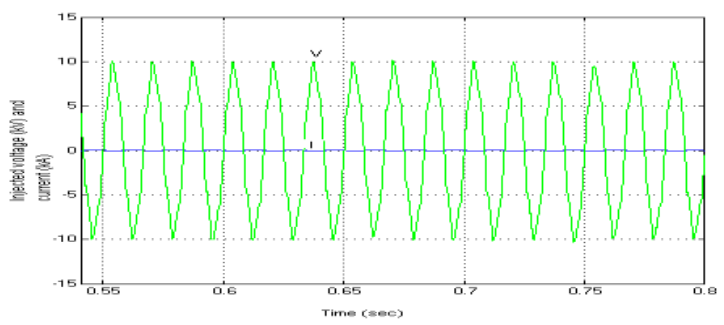

Figure 8. SSSC injected voltage and current for case (b)

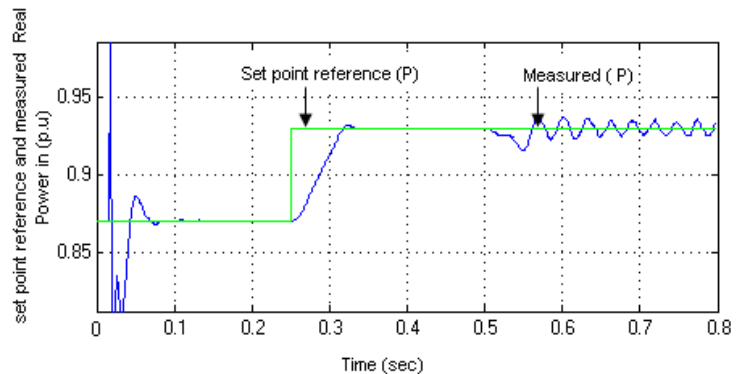

Figure 9. Real power flow over the transmission line for case (a)

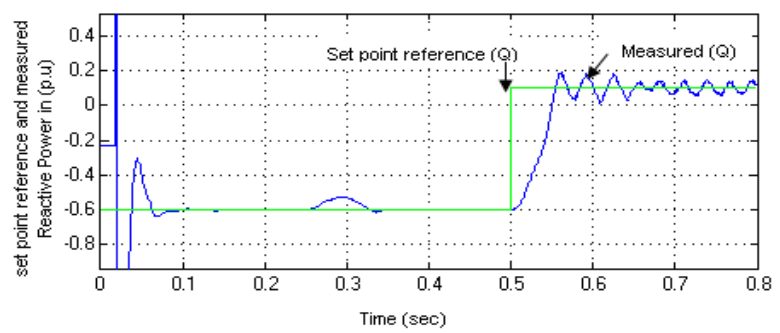

Figure 10. Reactive power flow over the transmission line for case (a)

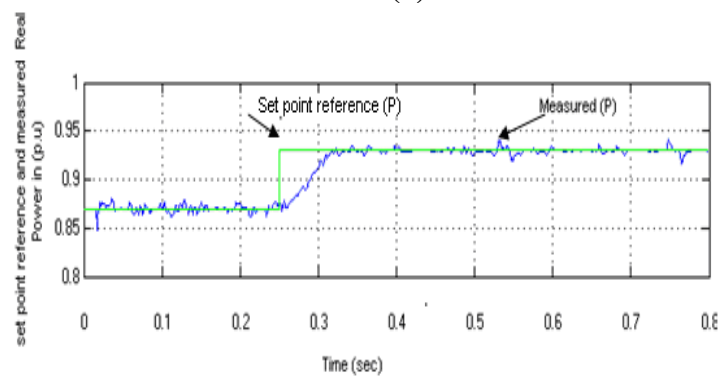

Figure 11. Real power flow over the transmission line for for case (b)

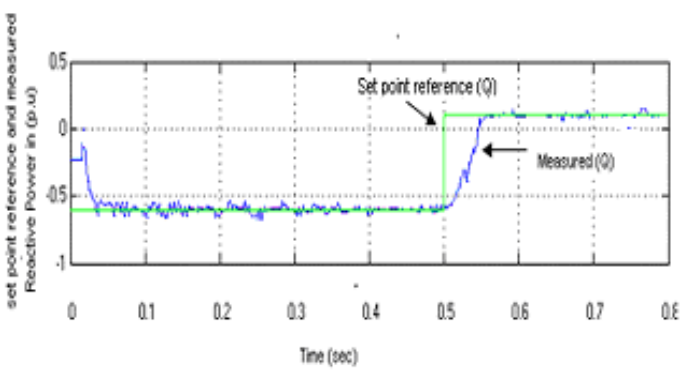

Fig. 12. Reactive power flow over the transmission line for for case (b)

The THD of the VSI output voltage for case (a) and (b) are shown in the figs. 13 and 14. It could be found that THD of the VSI output voltage is very much reduced for case (b) compared to case (a). 


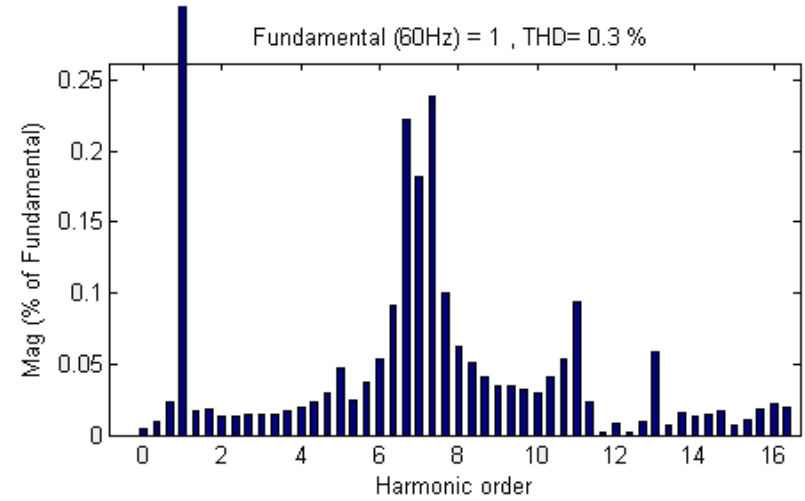

Figure 13. THD of 48-Pulse VSI output voltage for case (a)

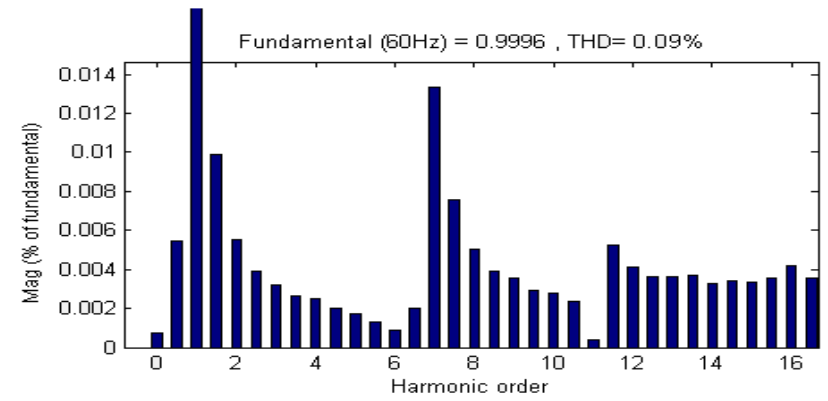

Figure 14. THD of 48-Pulse VSI output voltage for case (b)

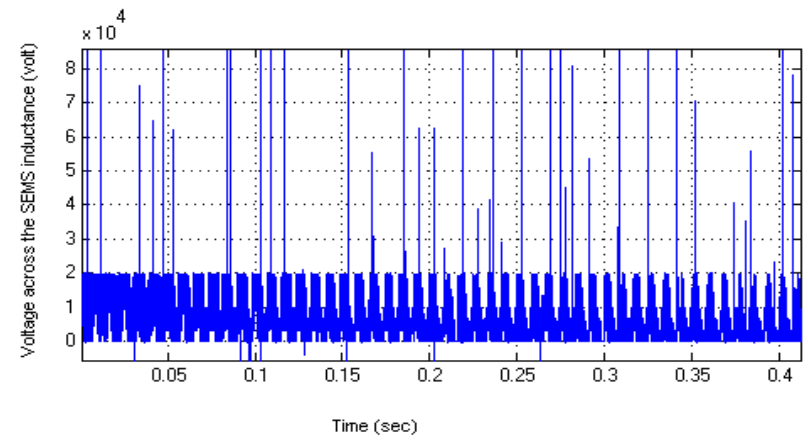

Figure 15. Voltage across SMES inductance

\section{CONCLUSION}

The dynamic performance of SSSC without and with SMES is analyzed with FGPI controller using Matlab/Simulink, where the SSSC is connected to a multi-area system. The SSSC is realized with 48 - pulse inverter and it generates symmetrical output voltages of desired magnitude and phase angle with very low harmonic components. It is inferred from the results that the FGPI controller performs effectively for the SSSC system with SMES compared to the SSSC system without SMES in order to maintain the real and reactive power flow over the transmission line to follow the set reference values under a step disturbance.

\section{ACKNOWLEDGMENTS}

We sincerely thank the Management, Secretary and Principal of Sona College of Technology, Salem for their complete support in doing this research work.

\section{REFERENCES}

[1] Hingorani, N.G., Role of FACTS in a Deregulated Market, Proc. IEEE Power Engineering Society Winter Meeting, Seattle, WA, USA, 2006, 1-6.

[2] An Intelligent Fuzzy controlled SSSC to Enhance power system stability-K.M Sze, L.A. Snider, T.S. Chung, K.W.Chan- 2004 International conference on Power System Technology, Powercon 2004 Singapore, 21-24 Novermber 2004 p1183 - 1188

[3] Anil. C. Pradhan and P.W. Lehn, Frequency domain analysis of the static synchronous series compensator, IEEE Transactions on Power Delivery, vol. 21(1), January 2006, pp. $440-450$.

[4] B. Geethalakshmi and P. Dananjayan, Investigations of Performance of UPFC without DC link capacitor, Electric Power Systems Research, vol. 78, Issue 4, pp. 736-746, April 2007.

[5] V.S.C. Raviraj and P.C. Sen, Comparative study of proportional - integral, sliding mode, and FLC for power converters, IEEE Transactions on Industry Applications, vol. 33 no. 2, March/April 1997, pp. 518-524.

[6] Bruce S. Rigby and R. G. Harley, "An improved control scheme for a series capacitive reactance compensator based on a voltage-source inverter," IEEE Trans. Industry Applications, vol. 34, no. 2, Mar./Apr.1998, pp. 355-363.

[7] Pavel Zuniga Haro and Juan M. Ramirez, "SSSC's Adaptive Neural Control", International Joint Conference on Neural Networks, July 16-21, 2006, p2267-2273.

[8] Lasseter R.H. and S. G. Lalali, "Dynamic Response of Power Conditioning Systems for Superconductive Magnetic Energy Storage," IEEE Trans. On Energy Conversion, 6, 3, 1991, pp. 388-393.

[9] J. M. Mendel, Fuzzy logic systems for engineering: a tutorial, Proc.IEEE 83 (3) (1995) 345-377.

[10] C.C. Lee, Fuzzy logic in control systems: fuzzy logic controller-part I IEEE Trans. Syst. Man Cybern. 20 (2) (1990) 404-418.

[11] C.C. Lee, Fuzzy logic in control systems: fuzzy logic controller-part I IEEE Trans. Syst. Man Cybern. 20 (2) (1990) 419-435.

[12] T. Tilli, Automatisierung Mit Fuzzy-Logic, Franzis-Verlag, M“unchen, 1992

[13] S. Tesnijak, S. Mikus, O. Kuljaca, Load-frequency fuzzy control in power systems, in: Proceedings of the Fifth SONT, Simpozij oNovim Tehnologijima, Poree, 1995, pp. 136-139.

[14] M.H. Hamza, P. Agathoklis, W.C. Chan, A Combined SelfTuning and Integral Controller for Load Frequency Control of Interconnected Power Systems, Regelungstechnik, Heft 7, Jahrgang 1982, pp. 226-232.

[15] J.D. Glover, F.C. Schweppe, Advanced load frequency control, in:IEEE Winter meeting, 30 January-4 February 1972, pp. 2095-2103. 